\title{
Expressões idiomáticas em textos jornalísticos: insumo para aulas de PLE
}

\author{
Maria Luisa ORTÍZ ALVAREZ \\ Universidade de Brasília \\ marialuisa.ortis@gmail.com \\ Ana Elizabete Barreira MACHADO'2 \\ Universidade Federal de Goiás \\ Secretaria de Educação do Estado de Goiás \\ annaellizza@hotmail.com
}

\section{Resumo}

O objetivo da nossa pesquisa foi analisar o potencial de insumo que os textos jornalísticos possuem e se poderiam ser utilizados como material autêntico na sala de aula de PLE, levando em consideração que muitas expressões idiomáticas neles contidas são constantemente usadas na mídia. Para a pesquisa propomos: 1) selecionar material autêntico, de jornais ou revistas, de onde seriam extraídas as expressões idiomáticas; 2) analisar as expressões selecionadas dentro do contexto em que estão inseridas; 3) elaborar uma proposta de exercícios com essas expressões para que pudessem ser utilizadas como insumo na sala de aula de PLE. Os resultados da pesquisa mostraram que os alunos estrangeiros têm muita dificuldade para compreender o significado das expressões idiomáticas, embora haja um contexto que possa sinalizar o sentido. Os textos jornalísticos podem ser uma fonte de insumo para o ensino das expressões idiomáticas, mas exigem uma boa preparação por parte dos professores. Este estudo poderá levar os professores participantes a uma reflexão sobre suas estratégias de ensino e à busca de novos procedimentos, de novos materiais que valorizem professores e alunos como sujeitos culturais que, ao interagir entre si e com os textos, possam trocar conhecimentos culturais e simbólicos diversos.

1 Professora doutora do Departamento de Línguas Estrangeiras e Tradução, do Instituto de Letras, da UnB.

2 Licenciada em Letras/Espanhol pela UnB, graduanda em Letras/Português pela UFG. 
Palavras-chave: expressão idiomática; português; língua estrangeira; textos jornalísticos, insumo

\begin{abstract}
The main objective of our research was to analyze the input potential that journalistic texts have and if they could be used as authentic material in a PFL (Portuguese Foreign Language) classroom, taking into consideration that many idiomatic expressions that they incorporate, are constantly used in the media. As a matter of research we propose: 1) the selection of authentic material, from magazines or newspapers, from which those idiomatic expressions can be extracted;2) the analysis of the selected expressions in the context they are inserted. 3) the elaboration of a proposal of exercises with these expressions to be used as input in PFL classroom. The results of the research show that foreign students have a lot of difficulty to understand the meaning of idiomatic expressions, although there is a context that indicates the meaning. Journalistic texts can be used as source of input to teach idiomatic expressions, but they demand that teachers prepare themselves adequately. This study can encourage the participating teachers to reflect on their teaching strategies and to search new procedures and materials that value teachers and students as cultural subjects who can exchange cultural and symbolic knowledge when interacting.
\end{abstract}

Keywords: idiom; Portuguese; foreign language; journalistic texts, input

\title{
1. Introdução
}

Quando aprendemos uma língua estrangeira (doravante LE), torna-se fundamental aprender as características culturais do povo falante dessa língua, seus costumes e valores. Por essa razão, faz-se necessário produzir materiais que incluam no seu repertório de tarefas, exercícios e atividades as frases idiomáticas, expressão viva do pensar coletivo. Considerando que o estudo da Fraseologia e sua inserção em sala de aula é importante para o ensino de língua-cultura ${ }^{3}$, na nossa pesquisa buscamos analisar alguns textos jornalísticos em que aparecem

3 De acordo com Kramsch (1996) língua deve ser ensinada como cultura, e não língua $e$ cultura, ou língua na cultura. Logo, entendemos que podemos ensinar cultura sistematicamente. 
expressões idiomáticas e mostrar que esses materiais autênticos podem ser utilizados como insumo na sala de aula de PLE, partindo do pressuposto de que a cultura e a língua de um povo são indissolúveis. A escolha do tema de inserção das expressões idiomáticas em sala de aula se deu por acreditarmos que o estudo dessas expressões pode enriquecer e facilitar o ambiente de ensino (ORTÍZ ALVAREZ, 2002, p. 42), pois, além de oferecer informação cultural, são um excelente material interativo na língua-alvo, e seu estudo revelará com maior propriedade os padrões culturais dos povos, seus sistemas de valores, etc. (XATARA, 2001, p. 58). Assim, faz-se necessário o ensino sistematizado de unidades fraseológicas (especificamente as expressões idiomáticas) de língua estrangeira, neste caso a portuguesa.

\section{Fundamentação teórica}

Para poder discutir a questão da inserção das expressões idiomáticas na sala de aula de PLE é preciso explicitarmos primeiro o que entendemos por expressão idiomática (doravante EI), em que área esse tipo de unidade está localizada e qual a produção científica desenvolvida neste campo do conhecimento humano.

A Fraseologia, especificamente a Fraseologia popular, como nos explica ORTÍZ Alvarez (2002, p. 91), estuda as frases feitas, locuções, refrães, provérbios, gírias e EIs, dentre outros. Alcaraz Varó e Martínez Linares (apud MONTORO DEL ARCO, 2005, p. 92) definem Fraseologia por meio de duas acepções:

1) Se dá o nome de "Fraseologia” à disciplina que tem por objeto o estudo das unidades fraseológicas (locuções, enunciados fraseológicos).

2) "Fraseologia" também se utiliza para referir ao objeto de estudo desta disciplina. Isto é, ao conjunto de "unidades fraseológicas" que estuda a "Fraseologia"4.

4 Texto original: “(1) Se da el nombre de 'Fraseologia' a la disciplina que tiene por objeto el estudio de las unidades fraseológicas (locuciones, enunciados fraseológicos). (2) 'Fraseologia' tambien se utiliza para referir al objeto de estudio de esta disciplina. Esto es, al conjunto de 'unidades fraseologicas' que estudia la 'Fraseologia". 
O Diccionario de la Real Academia Española (2001) contém a seguinte definição de fraseologia:

1) Conjunto de modos de expressão peculiares de uma língua, grupo, época, atividade ou individuo. 2) Conjunto de expressões intrincadas. Às vezes, palavreado. 3) Conjunto de frases feitas, locuções figuradas, metáforas e comparações fixas, modismos e refrões existentes em uma língua, no uso individual ou no de algum grupo ${ }^{5}$.

Ortíz Alvarez (no prelo) entende a Fraseologia como:

o conjunto de combinações de elementos linguísticos de uma determinada língua, relacionados semântica e sintaticamente, e que não pertencem a uma categoria gramatical específica e cujo significado é dado pelo conjunto de seus elementos. Nela se incluem todas as combinações onde os componentes possuem traços metafóricos geralmente estáveis (em alguns casos a estabilidade é parcial permitindo algumas alterações sem perder o significado total da expressão).

Assim, a Fraseologia é uma área que se ocupa dos estudos do léxico, especificamente as unidades fraseológicas, construções formadas por meio da combinação de dois ou mais elementos, com certo grau de fixação, cunhadas ao longo dos anos, cada uma com as suas características, e entre as quais estão incluídas as EIs. É necessário ressaltar que no século XX os pesquisadores russos foram os que mais se destacaram nos estudos fraseológicos.

De acordo com Ortíz Alvarez (2002, p. 199, apud PEDRO, 2007, p. 40), uma EI é:

a combinação (sintagma) metafórica de traços característicos próprios que se cristalizou pelo uso e frequência de emprego

5 Texto original: "1. Conjunto de modos de expresión peculiares de una lengua, de un grupo, de una época, actividad o individuo. 2. Conjunto de expresiones intrincadas, pretenciosas o falaces. Palabrería. 3. Conjunto de frases hechas, locuciones figuradas, metáforas y comparaciones fjadas, modismos y refranes, existentes en una lengua, en el uso individual o en el de algún grupo". 
(passando do individual para o social) numa determinada língua, apoiada na sua tradição cultural. Do ponto de vista estrutural, ela representa uma lexia indecomponível e está constituída de mais de uma palavra. Do ponto de vista semântico, o significado de seus elementos constituintes não corresponde ao sentido geral do todo, o sentido global do conjunto não é igual à somatória de suas partes; portanto, a interpretação semântica não pode ser calculada a partir da soma de seus elementos.

Xatara (1998, p. 170) define EI como "uma lexia complexa indecomponível, conotativa e cristalizada em um idioma pela tradição cultural". Para uma melhor compreensão do leitor, uma lexia complexa representa uma unidade locucional ou frasal.

Tomamos então por EI uma unidade locucional indivisível que, pelo constante uso em uma tradição cultural, tem um significado diferente da simples adição dos significados de suas partes; logo, tem caráter metafórico.

Assim, observamos que a tradição cultural é parte essencial do conceito de EI.Tal tema será nosso próximo tópico.

\subsection{Língua, cultura e expressões idiomáticas}

A cultura se refere às atitudes, às crenças, às maneiras de pensar, de se comportar e de lembrar fatos compartilhados pelos membros de uma dada comunidade. Kramsch (1996) afirma que a cultura se constitui em três contextos: o contexto diacrônico do tempo, o contexto sincrônico do espaço e o contexto metafórico da imaginação.

Kramsch (1998) assinala que a língua é o principal meio pelo qual conduzimos nossa vida social e que, em um contexto de comunicação, ela está interligada à cultura em múltiplas e complexas formas. A autora articula a simbiose entre língua e cultura sob três perspectivas. Na primeira, a língua expressa uma realidade cultural por ser o meio pelo qual um determinado grupo social expressa os fatos, ideias e eventos que fazem parte de um conjunto de conhecimentos sobre o mundo partilhado; ao mesmo tempo, reflete as atitudes, crenças e visões de mundo que também pertencem a 
outros do grupo. Em segundo lugar, ressalta que a língua incorpora uma realidade social ao possibilitar que os membros de uma comunidade ou grupo criem experiências por meio dela. Ao escolher a maneira como empregá-la, seja ao falar ao telefone, escrever um e-mail ou ler uma revista, as pessoas atribuem sentidos às suas experiências diárias através da língua. Os significados verbais e não verbais (escrita, fala, tom e altura da voz, pronúncia, estilo conversacional, gestos e expressões faciais, etc.), criados pelos membros do grupo, só se tornam compreensíveis devido à língua. E, por último, pontua que, sendo a língua um conjunto de signos, possui um valor cultural, isto é, simboliza uma realidade cultural que funciona para os seus falantes como uma forma de identificação deles mesmos e dos outros; porquanto, a língua é considerada um símbolo que marca suas identidades sociais.

Ao estudar as EIs não podemos deixar de pensar na relação línguacultura. Considerando que essa relação é inseparável, se torna indispensável para qualquer pessoa que queira aprender uma língua estrangeira o estudo ou o convívio com a cultura do(s) povo(s) que fala(m) essa língua. A língua é a mediadora da cultura; a cultura é interpretada pela língua; a cultura é conservada e relatada através da língua. Consequentemente, quando se fala em língua, fala-se em cultura, e quando se fala em cultura, fala-se em língua. Elas andam de mãos dadas. No entanto, para Kramsch (1996, p. 6), na realidade,"os professores ensinam língua e cultura, ou cultura na língua, mas não a língua como cultura". ${ }^{6}$ Assim, entendemos que as EIs devem ser ensinadas como língua-cultura na sala de aula de LE, pois elas juntamente com os outros fraseologismos são demonstrações claras da relação culturalíngua.

Entretanto, quando se trata da aprendizagem de uma LE, a aquisição das EIs se dá de forma muito diferente da aquisição de EIs de uma língua materna (LM). Na LE é necessária a sistematização do estudo dessas

6 Grifo nosso. No original: "In practice, teachers teach language and culture, or culture in language, but not language as culture." 
expressões (como queremos comprovar nesta pesquisa) e explicações a respeito do seu significado em contexto, pois, como falamos anteriormente, as EIs são fruto de uma tradição cultural e, se não forem explicitadas por alguém que conheça essa tradição, não serão compreendidas adequadamente pelo aprendiz que estuda a língua-alvo.

\subsection{Os textos jornalísticos}

A imprensa não é apenas um veículo de informação, mas também de ação e influência. O jornal, por exemplo, é capaz de criar no espírito do seu público o clima necessário para o efeito que pretende. Muitas vezes, estruturando a notícia, dá mais de um sentido ao texto. Em um determinado artigo jornalístico se apresenta uma confluência de sentidos, como podemos observar no exemplo: "computador nacional: gato por lebre". Neste, essa confluência é dada entre um dito popular ("gato por lebre") e uma declaração da indústria ("computador nacional é”) e entre esta e o ponto de vista do jornalista autor do artigo. No que se refere à exploração da expressão pertencente ao folclore nacional, gato por lebre (que significa ser enganado, comprar alguma coisa pensando ser outra), ela é apresentada numa manchete de jornal e transmite a dimensão do problema analisado com detalhes no decorrer do texto.

$\mathrm{O}$ jornalismo tem muito a oferecer aos leitores em termos de contato com a experiência cotidiana e o exercício de textualizar a realidade, utilizando metáforas e outras figuras de linguagem com a função de ilustrar, descrever e produzir conceitos. A compreensão dos textos jornalísticos supõe o reconhecimento da determinação sócio-histórica dos sentidos e a articulação entre os sentidos produzidos de acordo com a memória constitutiva dos domínios do saber.

Ter familiaridade com textos jornalísticos significa ter superado um forte obstáculo no acesso à informação e, indiretamente, à língua culta (se bem que muitos textos jornalísticos utilizam também a linguagem popular

7 COMPUTADOR nacional é gato por lebre, reclamam indústrias. Folha de São Paulo, 26 jun 1991.p. 1-13). 
para ironizar). Para os jovens, especificamente da faixa etária com que nós trabalhamos na universidade, a leitura dos jornais é praticamente diária. Eles passam os olhos por todas as manchetes e selecionam apenas aquelas que são do seu interesse. Há também o prazer de descobrir novidades e saciar a curiosidade em relação a detalhes sobre notícias já veiculadas anteriormente em rádios e TVs. Manter todas essas fontes de interesse resulta em um aspecto essencial quando vai ser utilizado o jornal em sala de aula. Nesse sentido, o professor poderia escolher as manchetes de interesse que incluam EIs e levá-las à sala de aula, trabalhar e explorar esse material que pode ser um insumo rico para ensinar língua-cultura.

Analisando essa necessidade do ensino das EIs nas aulas de LE, elaboramos uma proposta de exercícios de interpretação textual, utilizando textos jornalísticos com EIs em suas manchetes.

\section{Metodologia}

Nossa pesquisa é de natureza qualitativa. As pesquisas qualitativas são caracteristicamente multimetodológicas, e os dados não são coletados de forma numérica. A observação (participante ou não), os questionários, a entrevista em profundidade e a análise de documentos são os instrumentos mais comuns nesse tipo de pesquisa, embora possam ser complementados por outras técnicas. No nosso caso, fizemos uma pesquisa documental para a escolha dos textos jornalísticos que fariam parte da proposta de exercícios com EIs e que seriam utilizados em sala de aula de PLE como fonte de insumo. Também aplicamos questionários aos professores e alunos, fizemos observação de aulas com notas de campo e elaboramos uma proposta de exercícios para demonstrar a viabilidade e benefícios do trabalho com textos jornalísticos que incluíssem EIs. Os participantes da pesquisa eram alunos de um curso de português para falantes de outras línguas, de diferentes faixas etárias e de nível avançado. Tanto os professores quanto os alunos foram muito receptivos e mostraram disposição para colaborar com a nossa pesquisa, o que nos permitiu desenvolver nosso trabalho e poder comprovar 
a necessidade de uma sistematização do estudo de EIs no processo de ensino-aprendizagem de uma LE.

\section{Análise dos dados}

Durante as observações das aulas, acompanhamos o trabalho dos professores com as unidades fraseológicas, principalmente com as EIs. Um dos objetivos da pesquisa era elaborar uma proposta de exercícios que, apresentada aos professores, estes a incluíssem em seus planos de aula e os testassem nas suas turmas.

No caso do primeiro exercício, além da atividade de interpretação da EI que havíamos proposto para os alunos, era necessário explicar o significado da palavra "escanteio" na expressão "jogado para escanteio" (extraída da manchete "[deputado] Moraes é jogado para escanteio", do Jornal Correio Braziliense, em 11 de maio de 2009), pois não era de seu conhecimento. Nesse exercício, observamos respostas diferentes, algumas com um significado próximo do significado real, entretanto incompleto, com relação ao real sentido (semântico) da EI.

Em uma das respostas encontramos a seguinte explicação: "O deputado foi ignorado, sua opinião não foi considerada”. Vemos aqui que a ideia está correta, mas ainda incompleta, porque além de ignorado, e sua opinião não ser considerada, o deputado foi retirado da situação. Outra resposta foi: "suas sugestões não foram aceitas". De novo observamos uma interpretação incompleta, pois não foi aceita a opinião do deputado, foi ignorada, além de ser retirado do processo. Outro dos participantes da pesquisa trouxe uma interpretação bem diferente. Ele diz: "indica que o deputado está a ponto de fazer uma declaração importante ou acusação”. Aqui o aluno entendeu o contexto, entretanto não compreendeu o significado da EI. Outra resposta interessante foi: "ele trabalha de longe ou ele vê tudo de lado e passa para outros. Ele vê todos e joga para um”. Aqui a interpretação foi totalmente relacionada à imagem do escanteio ou ao significado de uma das palavras que integram a EI. Assim, percebemos 
a dificuldade dos alunos para entender a expressão, pois, como já explicitamos ao definir o conceito de EI, elas são indecomponíveis, ou seja, não podem ser compreendidas pela soma dos significados literais dos seus elementos.

No segundo exercício que propomos, além da manchete colocamos o trecho de um texto jornalístico e embaixo do texto apresentamos algumas palavras que muito provavelmente os alunos não conheciam. No texto aparecia a EI "sem dó nem piedade" ("O método escocês [dieta]: sem dó nem piedade", texto extraído da revista Veja, de 27 de maio de 2009), de mais fácil compreensão para a maioria. Perguntamos aos alunos qual seria o significado, qual a intenção do autor do texto. Apenas um participante da pesquisa entendeu que "dó" e "piedade" eram uma repetição, apresentada para trazer uma ideia reforçada de que fazer tal dieta era muito difícil. Perguntamos também se pelo contexto em que estava inserida a expressão era possível compreender se a dieta era fácil ou difícil. Nessa ocasião, todos os alunos responderam que era difícil.

No último exercício ${ }^{8}$ constatamos como se dá, à primeira vista, o contato do aluno estrangeiro com uma EI da língua-alvo. Primeiro ele tenta compreender a expressão a partir do significado de cada um dos componentes da EI, mas, como já falamos anteriormente, o significado da expressão não se pode deduzir da soma do significado de cada um dos seus componentes. A segunda tentativa é entender pelo contexto no qual a EI está inserida.

A expressão utilizada dessa vez foi "comer o pão que o diabo amassou" (extraída da Agência Estado - online, de 24 de março de 2009). Na interpretação de todos os participantes, os prefeitos que "comiam o pão que o diabo amassou" estavam fazendo algo errado. Um deles explicou que, para comer o pão que o diabo amassou, tal pessoa deveria ser companheiro do diabo, por estar à mesa com este. Daí surgiu a ideia de que os prefeitos eram "cúmplices do diabo", ou seja, estavam fazendo algo errado. Mas o

8 Cf. anexo 1. 
verdadeiro sentido dessa EI é o contrário, pois os prefeitos que "comeram o pão que o diabo amassou” eram as vítimas e não os culpados. Outra pergunta que fizemos era se a situação dos prefeitos era boa ou ruim, e todos compreenderam que era ruim. Também perguntamos se eles se lembravam de alguma EI parecida em seus idiomas maternos, mas nenhum deles conseguiu se lembrar.

\subsection{Os questionários}

Além dos exercícios propostos e das observações das aulas, aplicamos questionários aos professores e alunos.

No questionário das professoras, a primeira pergunta que fizemos foi "Como você entende a relação língua-cultura?". Observamos que as professoras compreendem a relação língua-cultura como aspecto fundamental a ser levado em conta no ensino de uma LE, que a cultura está intrinsecamente ligada à língua e que uma aula de LE deve refletir sobre a cultura-alvo. Não é possível ensinar uma LE se não a compreendermos como um fenômeno cultural, marcado pela especificidade da própria língua, enquanto língua-cultura, que a faz ser diferente e depender do contexto em que é utilizada. Ao interagir com outras culturas, o sujeito coloca em questão padrões culturais próprios, o que pode promover processos de aprendizagem pessoal e de transformação sociocultural.

A segunda pergunta foi "O que você entende por expressão idiomática?". As professoras responderam que essas expressões formam parte da cultura de cada comunidade. Uma das professoras colocou como destaque a necessidade, no caso dos estrangeiros que estudam uma LE, uma "explicação maior e mais detalhada" das EIs em sala de aula.

Sobre a relação entre EI, língua e cultura, observamos que as professoras compreendem essa relação, que a EI é expressão da cultura e há a necessidade do ensino dessas e outras unidades fraseológicas nas aulas de LE para um melhor desenvolvimento da competência comunicativa. Uma das professoras sugeriu o estudo das EIs também na língua materna. 
Sobre a utilização dos textos jornalísticos em sala de aula, as professoras responderam que são muito usados, pois é uma forma de se trabalhar com textos autênticos e atuais, entretanto é preciso adequar o tipo de texto ao nível de aprendizagem dos alunos.

$\mathrm{Na}$ última questão, abordamos o tema central de nosso estudo, se a proposta de utilização de textos jornalísticos com EIs foi bem aceita na sala de aula e se esses textos constituem uma fonte de insumo compreensível para as aulas de PLE. Uma professora afirmou que achou a "ideia inovadora e interessante", apesar de não ter visto os resultados exercícios dos alunos. Outra professora, além de apoiar a iniciativa, ressalta que os textos jornalísticos com EIs são “textos com a língua em situação real de uso”.

Assim, de acordo com as respostas das professoras, os textos jornalísticos são um ótimo insumo para aprendizagem de uma LE. Constatamos, entretanto, que além dos exercícios sempre é necessária, após a tentativa dos alunos de interpretação da EI, uma explicação do significado.

Quanto aos questionários dos alunos ${ }^{9}$, observamos na primeira pergunta uma resposta que se aproxima do conceito de EI que utilizamos neste artigo: "É aquela expressão que não é possível identificar seu significado no sentido literal." Quanto à segunda pergunta, as respostas foram sucintas, afirmando que é importante aprender as EIs para um melhor desenvolvimento da competência comunicativa na língua portuguesa.

Sobre a frequência de uso das EIs por parte dos falantes nativos, todos responderam que é muito frequente ouvir nas ruas, na TV, e que nem sempre é possível compreender seu significado pelo contexto, sendo necessário pedir para o nativo explicar o significado da expressão utilizada.

\section{Considerações finais}

A partir dos resultados da pesquisa, constatamos a necessidade dos aprendizes de português como língua estrangeira de estudar e compreender

9 Cf. anexo 2. 
as EIs como expressão da relação língua-cultura. Assim, deve haver uma conscientização por parte dos autores de livros didáticos para que sejam incluídas e sistematizadas essas e outras unidades fraseológicas nos materiais didáticos. Esses livros representam, se não a principal, uma das mais importantes fontes de conteúdo relevante, que promove a aprendizagem, mas podem, por outro lado, servir como bloqueio no desenvolvimento da competência comunicativa, e, portanto, não promover interação e, consequentemente, a aprendizagem.

De maneira geral, os materiais disponíveis não incentivam as relações interculturais, pois apresentam informações estanques da cultura da línguaalvo. Eles também devem organizar as suas atividades e tarefas dentro de ambientes propícios, para a prática comunicativa da língua-cultura, e deslocar o foco na estrutura para o uso comunicativo da língua-cultura, para as necessidades e interesses dos alunos e as dificuldades e/ou necessidades observadas pelo professor no processo de aprendizagem.

Por outro lado, os professores de LE também têm que fazer a sua parte, ensinando as EIs dentro de seus contextos de uso, com a ajuda de textos autênticos como, por exemplo, os jornalísticos. Muitos professores, por falta de tempo ou de conhecimento, acabam não explorando os textos autênticos vindos de outras fontes para que os alunos possam ter a oportunidade de familiarizar-se com outros discursos e formas de aprendizagem intercultural enquanto estão desenvolvendo as suas habilidades linguísticas. Mesmo utilizando textos que servem claramente como "pretexto" para a fixação de determinadas estruturas gramaticais, é possível uma discussão sobre aspectos culturais, e esta pode ser na língua materna, caso o grupo de alunos ainda não possua um bom nível de proficiência linguística na língua-alvo, que permita tal discussão.

Enquanto uma reorganização dos livros didáticos não se torne possível, o professor pode facilmente encontrar informação cultural em outras fontes: na mídia (TV, artigos de revista, comerciais, tiras cômicas, etc.), na literatura (teatro, romance, fábulas, poemas, etc.), na música, vídeos e realia (panfletos de supermercados e lojas, guias turísticos, etc.). Mas é preciso 
que haja, antes de tudo, uma mudança no modo de pensar dos professores de LE sobre como a língua funciona e sobre os objetivos do ensino de LE, o que, por sua vez, implica na atualização de sua formação profissional por meio de cursos de formação continuada e participação em eventos da área que promovam tal discussão.

É importante também que os grupos de pesquisa em Fraseologia continuem investindo nessa área do conhecimento por meio de pesquisas que mostrem caminhos e estratégias para a inserção das unidades fraseológicas na sala de aula de língua estrangeira.

Entendemos, por fim, que o estudo das EIs (e de outros fraseologismos) deve ser sistematizado no processo de ensino de português como língua estrangeira e em qualquer outra língua que esteja em situação de LE. Da mesma maneira, acreditamos que a utilização de textos jornalísticos em sala de aula é um insumo adequado para o desenvolvimento da competência comunicativa dos alunos.

Os resultados dessa pesquisa também apontam para a urgência de uma reflexão e redefinição das práticas pedagógicas em LE, direcionada para o desenvolvimento da competência intercultural, pois é necessário que o educando aprenda a interpretar o outro apoiado no conhecimento que ele tem da outra cultura, desenvolvendo-o como pessoa e despertando seu senso crítico.

\section{Referências}

KRAMSCH, Claire. The cultural component of language teaching. Zeitschrift für Interkulturellen Fremdsprachenunterricht. v. 1, n. 2, 1996. Disponível em: <http://zif.spz.tu-darmstadt.de/jg-01-2/beitrag/kramsch2. htm>. Acesso em: 11 nov 2011.

. Language and culture. Oxford: Oxford University Press, 1998.

MONTORO DEL ARCO, Esteban T. Aproximación a la bistoria del pensamiento fraseológico español: las locuciones con valor gramatical en 
la norma cultural. Tese (Doctorado en Lengua Española) - Facultad de Filosofía y Letras, Departamento de Lengua Española, Universidad de Granada, Granada, 2005.

NOGUEIRA, Luis Carlos Ramos. A presença de expressões idiomáticas na sala de aula de espanhol/lingua estrangeira para brasileiros. Dissertação (Mestrado em Linguística Aplicada) - Departamento de Línguas Estrangeiras e Tradução - Universidade de Brasília, Brasília, 2008.

ORTÍZ ALVAREZ, Maria Luisa. Expressões idiomáticas do português do Brasil e do espanhol de Cuba: estudo contrastivo e implicações para o ensino do português como língua estrangeira.Tese (Doutorado em Linguística Aplicada) - Instituto de Estudos da Linguagem, Universidade Estadual de Campinas, Campinas, 2000.

. Os fraseologismos como expressão cultural: aspectos de seu ensino em PLE. In: CUNHA, Maria Jandyra C.; SANTOS, Percilia. (Org.). Tópicos em português língua estrangeira. Brasília: Editora Universidade de Brasília, 2002.p. 157-172.

- As metáforas na construção do significado das expressões idiomáticas. Horizontes de Lingüística Aplicada, Brasília, a. 3, n. 1, 2004.

- As expressões idiomáticas nas aulas de ELE: um bicho de sete cabeças? In: REY, Isabel G. (Org.). Les expressions figées en didactique des langues étrangères. Paris: 1e ed.v. 1, p. 159-179, E.M.E Editions, 2007.

- A lingua(gem) nossa de cada dia: o componente fraseológico no ensino de línguas próximas (ELE e PLE), no prelo.

PEDRO, Magali L. As expressões idiomáticas no ensino de português como lingua estrangeira para estudantes uruguaios. Dissertação (Mestrado em Linguística Aplicada) - Departamento de Línguas Estrangeiras e Tradução, Universidade de Brasília, Brasília, 2007.

REAL ACADEMIA ESPAÑOLA. Diccionario de la Real Academia Española. 2001. Disponível em: <www.rae.es $>$. Acesso em: 11 nov 2011. 
RONCOLATTO, Eliane. A análise semântica como fonte para o entendimento do processo de formação de expressões idiomáticas: em foco o português e o espanhol. Anuario Brasileño de Estudios Hispánicos, v. 13, 2003. p. 77-84.

XATARA, Claudia Maria.A tradução para oportuguês de expressões idiomáticas em francês. Tese (Doutorado em Linguística e Língua Portuguesa) Universidade Estadual Paulista Júlio de Mesquita Filho, Araraquara, 1998.

. O ensino do léxico: as expressões idiomáticas. Trabalhos em Lingüística Aplicada, Campinas, Universidade Estadual de Campinas, n. 37, p. 49, 2001.

. Expressões idiomáticas: mecanismos de tradução. UNESP, s/d. 


\section{ANEXO 1}

Este exercício faz parte do projeto de pesquisa intitulado Expressões idiomáticas nos textos jornalísticos: uma possivel fonte de insumo para as aulas de português como lingua estrangeira, elaborado por Ana Elizabete Barreira Machado e orientado pela Profa Dra Maria Luisa ORTÍZ Alvarez. Sendo assim, pedimos a sua colaboração, pois a sua participação é fundamental para o nosso trabalho.

\section{Exercício com expressões idiomáticas}

\section{Leia o texto abaixo e responda:}

"Lula: prefeitos estão comendo pão que o diabo amassou"

O presidente Luiz Inácio Lula da Silva voltou a prometer hoje que vai "olhar com muito carinho" a questão da queda dos valores do Fundo de Participação dos Municípios (FPM). "Sei que vocês [prefeitos] estão comendo o pão que o diabo amassou por causa disso, mas quero deixar claro que para nós [governo federal] não adianta que os municípios estejam mal", afirmou ele [...].

Fonte: Agência Estado. Disponível em: <http://br.noticias.yahoo.com/s/24032009/25/ politica-lula-prefeitos-estao-comendo-pao.html $>$.

a) Identifique a expressão idiomática no texto.

b) Sabendo que amassar, é preparar a massa, tornar algo em massa, e sabendo que o diabo é o ser menos querido numa cultura cristã, como você entende essa expressão "comer o pão que o diabo amassou"?

c) Pensando nessa expressão, os prefeitos estão em uma situação boa ou ruim?

d) Na sua língua materna existe alguma expressão parecida? Qual? 


\section{ANEXO 2}

\section{QUESTIONÁRIO AOS ALUNOS}

Este exercício faz parte do projeto de pesquisa intitulado Expressóes idiomáticas nos textos jornalísticos: uma possivel fonte de insumo para as aulas de português como lingua estrangeira, elaborado por Ana Elizabete Barreira Machado e orientado pela Profa Dra Maria Luisa ORTÍZ Alvarez. Sendo assim, pedimos a sua colaboração, pois a sua participação é fundamental para o nosso trabalho.

1. O que você entende por expressão idiomática?

2. Você acha que é importante aprender expressões idiomáticas para desenvolver sua competência comunicativa na língua portuguesa?

3. Você costuma ouvir muitas expressões idiomáticas do português no seu dia a dia (em jornais, conversas, TV, etc.)?

4. É possível entendê-las pelo contexto?

5. Quando não é possível entender a expressão idiomática pelo contexto, você pede ao seu interlocutor que explique o que significa? 